\section{MRC and peer review}

SIR-As a clinician, I am appalled by the Medical Research Council (MRC)'s lack of support for work that has direct potential for advances in the clinical care of patients.

The question that Dr David Rees does not answer in his response to your leading article "Untransparent grants" (Nature 346, 684; 1990) is "How does the MRC measure the merits and demerits of individual proposals?" The traditional mechanism is peer review: literally, judgement by equals, which in this context must mean authorities with an equal ability to judge the science under review - experts in the specifics of the subject. Although one would not normally expect this to be so, in the actual case that sparked off your leading article, there was unanimity of view among the peers - that the science was of high quality and of clinical importance, and should be supported - yet the $\mathrm{MRC}$ rejected this judgement.

Clearly, the MRC is unable to finance, at the level that the science itself justifies, all the work that is highly rated by peers. Rather than spread the hardship evenly, the MRC has chosen to deal with this situation by discontinuing excellent teams in some fields while sparing others in a harsh all-or-none policy. If the MRC is now saying that such decisions between fields are based on measurements of the quality of science in each field, then we need to know how these extraordinarily difficult measurements are made and what precision they are thought to have. Many will doubt that such measurements are possible: these are subjective value judgements, not precise measurements of physical properties. Moreover, logic dictates that what is excellent in one field remains excellent, whatever the competition for funds.

\section{Clinical trials}

SIR-I would like to correct statements in the News story headlined "Clinical trials" (Nature 345, 754; 1990). The policy recommended by the Advisory Committee on Women's Health Issues (ACWHI) on including women as study subjects was published in the National Institute of Health (NIH) Guide to Grants and Contracts in 1986 and again in 1987. The article mentions two internal surveys indicating that sexual imbalances existed in research within NIH, following which ACWHI sent new recommendations to the director of NIH. I am unaware of any internal surveys on this subject during this period.

The ACWHI did submit a report on NIH support for research on women's health issues (defined as diseases and conditions unique, more prevalent, more
I believe that the judgements now being made are not of this sort at all, nor are they peer judgements, but management decisions taken to achieve specific policy objectives within a given financial structure. This has now been admitted by Rees himself, in his interview with the British Medical Journal $(\mathbf{3 0 1}, 508 ; 1990)$ when he makes it clear that it is now MRC policy to throw the peers' opinions out of the window if the nine-man MRC strategy committee so decides.

The MRC is a publicly accountable body, and the manner in which its funding decisions are now being made should be approved by the public. If the present situation continues, not only the reputation of the MRC, but also that of British medical science, will certainly suffer.

ROY CALNE University of Cambridge Clinical School, Department of Surgery,

Level 9, Addenbrooke's Hospital, Hills Road, Cambridge CB2 2QQ, UK

SIR - Please add my voice to those protesting at the forthcoming closure of the MRC Medical Cryobiology Unit in Cambridge (Nature 364, 685; 1990).

Although I know little of the circumstances influencing the decision to close this unit, the council's other research priorities or the marketability of the work undertaken in Cambridge, I am familiar with both the Cryobiology Unit in Cambridge - having undertaken a 'sandwich' year there as part of my degree course and cryobiology internationally. I can therefore appreciate the high esteem in which the work performed at Cambridge is held by the 'cryobiology community' and the long-term (but perhaps not immediate) benefits of the pioneering research into several aspects of cryopreservation

serious, having different causes or interventions in women or some subgroup of women) in August 1989, the month after Dr Wyngaarden left. The committee recommended that the policy published for grants and contracts also be applied to the NIH intramural research programme. Unfortunately, that recommendation was not brought to the attention of the responsible officials. Although data show equal access for men and women to research conducted in the clinical centre at NIH, adoption of a stated policy on including women is now under discussion.

IRIS J. SCHNEIDER

(Assistant Director for Program Operations and Planning, $\mathrm{NCl}$ \& Co-Chair, NIH Advisory Committee on Women's Heaith Issues)

National Institutes of Health,

National Cancer Institute,

Bethesda, Maryland 20892, USA performed there.

My own time at the unit was most constructive, gave me a sound base in science and an invaluable launch to my career.

M. J. BENTON

Rue de la Poste,

St Ouen les Vignes,

37530 Amboise, France

\section{No cancer link}

SIR-In a recent News article ${ }^{1}$, reference is made to a draft report from the US Environmental Protection Agency (EPA) concerning a supposed link between exposure to extremely low-frequency (ELF) electromagnetic fields (EMF) and cancer. The article quotes from the report: "The consistently repeated pattern of lymphoma, leukemia and brain cancer in the childhood studies and the ruling out of several confounding exposure factors in the Savitz et al. study (Am. J. Epidemiol. 128,$21 ; 1988$ ) argue in favour of a causal link between these tumor types in children and exposure to ELF magnetic fields or electric fields." There are several misconceptions in this statement.

The inconsistency of findings reported by investigators working on this topic does not support the argument of a causal link. Regarding possible confounding exposure factors, Savitz and Feingold ${ }^{2}$ found that the incidence of childhood cancer was associated with traffic density. Increased risks for total number of cancers and leukaemias were related to increased traffic densities. The data were obtained during the same study of EMF and cancer cited by EPA. The odds ratios for these associations were greater than those reported earlier for EMF and cancer. In another study often quoted as being evidence of a link", "cases were found to generally live closer to high traffic routes". One potential consequence of high traffic density is a high level of benzene ${ }^{4}$, which is a well-established cause of leukaemia.

Cartwright ${ }^{5}$ summed it up best when he stated: "Our present scientific knowledge points at the very best to a minute risk of EMF verging on the point of nonexistence." The unsubstantiated claims of a link between EMF and cancer should not lead readers to believe that a hazard exists.

JAMES R. JAUCHEM

Radiation Sciences Division,

US Air Force School of Aerospace Medicine,

Brooks Air Force Base,

Texas 78235-5301, USA

1. Shulman, S. Nature 345, $463(1990)$

Savitz, D. A. \& Feingold, L. Scand I. Work Environ. Hith 15 $360-363(1989)$

3. Wertheimer, N. \& Leeper, E. Am. J. Epidemiol. 109, 273 284 (1979)

4. Stenberg, U., Alsberg, T. \& Westerholm, R. Environ. Hith Perspect. 47, 53-63 (1983).

5. Cartwright, R. A. Br. J. Cancer 60, 649-651 (1989) 